\title{
Demand of Governmental Employees for Social Health Insurance and Associated Factors in Takusa woreda, Amhara National Regional State, Ethiopia
}

\author{
Tamyalew Getahun \\ University of Gondar \\ Getasew Amare \\ University of Gondar \\ Mezegebu Yitayal \\ University of Gondar \\ Amsalu Feleke \\ University of Gondar
}

Mekuanint Alemneh ( $\nabla$ yageta23@gmail.com )

University of Gondar https://orcid.org/0000-0002-5038-700X

\section{Research}

Keywords: Demand, Employees, Social Health Insurance, Takusa Woreda, Ethiopia

Posted Date: January 26th, 2021

DOI: https://doi.org/10.21203/rs.3.rs-152714/v1

License: (c) (1) This work is licensed under a Creative Commons Attribution 4.0 International License. Read Full License 


\section{Abstract}

Objective: The main aim of this study was to assess the demand of governmental employees for social health insurance and associated factors in Takusa district, Northwest Ethiopia.

Methods: Institution-based cross-sectional triangulated with the phenomenological study was conducted. A simple random and a purposive sampling technique were used to recruit 324 employees. Binary logistic regression was performed, and $\mathrm{P}<0.05$ was considered statistically significant. In the qualitative study, data were analyzed using thematic analysis.

Results: $61.1 \%$ of employees had a good demand for social health insurance. Employees who had 5-6 family sizes were 5.5 times more likely to have a demand for $\mathrm{SHI}$ than counterparts. Also, employees who live in a rural area were 3.3 times more likely to have SHI demand than urban residents. In the qualitative analysis, lack of awareness, fear of poor-quality health service provision, the unpreparedness of health institutions, lack of inputs, poverty etc. were the main constraints for the poor demand for SHI.

Conclusion: In general, the higher demand for SHI in this study was more than half of the Ethiopians but less than abroad. Therefore, the concerned body shall intervene on the factors by implementing a SHI program cooperatively.

\section{Background}

In the world, there are different health insurance $(\mathrm{HI})$ like social health insurance $(\mathrm{SHI})$, community-based health insurance $(\mathrm{CBHI})$, national health insurance $(\mathrm{NHI})$, and private health insurance $(\mathrm{PHI})$. Citizens in the informal and agriculture sectors are being membership of $\mathrm{HI}$ with the $\mathrm{CBH}$ system while private sectors are covered by the PHI program. Health insurance was introduced in Germany by Bismarck in 1883 followed by Austria, Belgium, English, and the Netherlands within 1887-1941. CBHI was started in 1990 in Ruanda, Senegal, Mali, Uganda, Tanzania, and Ghana. SHI and CBHI differ from private health insurance in that the contribution of funds mandated and enforced by the state [1-4].

Due to poverty, people in the world lack sufficient health service especially in developing countries. According to WHO, 150 million people globally suffer from financial problem each year and 100 million were pushed into poverty due to direct payments for health services [5]. Lack of awareness, administrative difficulties, quality of health service provision, poverty, presence of many informal workers, presence of dispersed rural population, disproportional growth of population and health coverage, shortage of infrastructure and qualified human resource are main challenge in the world to afford $\mathrm{HI}$ [6]. In low-income countries, reliable information on existing treatment coverage for mental disorders was unavailable [7].

SHI provides financial protection against unexpected health care costs and to enhance access to modern health care. It redistributes from the healthy to the sick, rich to the poor, younger to elderly and small 
families to large families [8]. Insurance increases the number of prenatal care visits by $24 \%$ relative to being uninsured, holding the other constraints constant [9].

Health insurance was introduced into Ethiopia by proclamation number 191/2011. CBHI program had been launched in selected 13 woredas in Debube, Oromia, Amhara, and Tegere. Health coverage in these areas was $47 \%[2,5,10-11]$ but SHI was not yet started. In Ethiopia, the Federal Ministry of Health (FMOH) would launch 3 types of health insurance systems (HIS) which are $\mathrm{CBHI}, \mathrm{PHI}$, and SHI. When situations will be stabilized, it will be unified into NHI [2]. In our country, SHI involves the mandatory collection of money from formal sector employees both public and private as the monthly gross salary of $3 \%$ from employees and $3 \%$ from his employers, $1 \%$ from retires, and $1 \%$ from Government Pensioners [10]. SHI is the universal financial protection from medical expenses and providing quality health care services access to employees [11]. It provides health insurance coverage for those who employed for 3 months and above in all governmental and non-governmental organizations, retires, private Sector Enterprises with greater than 9 employees and their families (husband, wife, healthy children under 18 years old, disabled children above 18 years old, excluding defense forces [1].

Services intended to provide through SHI includes outpatient and inpatient services, deliveries, surgical services, generic drugs, and laboratory diagnosis. But the disease that is not public health importance and those covered by other laws (traffic accidents, occupational injuries), exempted health services, and expensive treatments which affect the sustainability of the system are excluded [1-3]. Ethiopia had 90 million populations which $15 \%$ are urban dwellers, and per capita, gross national income had reached US\$470 in 2013 [12]. Over $27.8 \%$ of the population was estimated to live below the poverty line in 2011/12 [13]. In 2014, the life expectancy of Ethiopians was 64 years [14]. Health service coverage of Ethiopia was $87 \%$ in 2015 [13]. The Source of income for health service provision in Ethiopia was $21 \%$ from the government, $40 \%$ from Non-governmental organizations (NGOs), 37\% from service receivers, and $2 \%$ from insurance and others [1]. Per capita health spending of Ethiopia, 24.5\% US\$ in 2013, was far from the World Health Organization (WHO), US\$60, recommended to low-income countries like Ethiopia $[1,13]$.

In Ethiopia, FMOH had ratified to implement the SHI program [15]. Almost $80 \%$ of morbidity in Ethiopia was due to preventable diseases that were associated with low socioeconomic development [16]. SHI is financial protection against catastrophic medical expenses in an equitable, efficient, and sustainable manner; all people have access to services and do not suffer financial hardship paying for them. In our country, there were no adequate studies, especially in Takusa woreda. Therefore, this study intended to assess the demand for social health insurance and associated factors in Takusa woreda, Amhara National Regional State, Ethiopia.

\section{Methods}

\section{Study design, area, and period}


This study was an institution based quantitative cross-sectional triangulated qualitative phenomenological method conducted in Takusa woreda from September to October 2015. It lies $738 \mathrm{~km}$ away from Addis Ababa, the capital city of Ethiopia, and $90 \mathrm{~km}$ from Gondar City. The area of the Woreda was $190,283 \mathrm{~km} 2$ with a total population of 166,530 , of which $2024(1.22 \%)$ were governmental employees. The Woreda had 25 kebeles, 1 District hospital, 5 health centers, 26 health posts, 6 clinics, and 5 pharmacies. The total health professionals were 181,34\% were health extension workers, $44 \%$ Nurses, $7 \%$ laboratory personnel, $7 \%$ pharmacists, $4 \%$ midwives, and $4 \%$ are others like health officer, environmental health, General practitioners, and $1 \mathrm{X}$-ray technician. The health coverage of the Woreda was $95 \%$ [17].

\section{Source and study Populations}

The source population was all Takusa Woreda governmental employees while the study population was employees who stayed a minimum of 6 months on employment in any place but currently employed in Takusa woreda.

\section{Sample size and sampling technique}

The sample size calculated based on the single population proportion formula by assuming $95 \%$ confidence interval (Cl), 5\% marginal error (d), 2,024 total population of Takusa woreda civil servants=N), $5 \%$ non-response rate, $54 \%$ single population proportion $(\mathrm{P})$ for the demand of $\mathrm{SHI}$ in Wolita Sodo town [24]. Based on the above assumptions, the final sample size to be enrolled in this study was 337 governmental employees. In the case of qualitative study design, FGD with key pling technique was used for quantitative and qualitative study design, respectively.

\section{Data collection procedures}

In the case of quantitative study design, all governmental employees' list (frame) was obtained from Takusa woreda Finance Office. Here, their name was ordered alphabetically and selected randomly by computer among all sectors. Then by providing employees' address, working institution, data collectors were departed into each institution and introduced themselves including the purpose of the study to the selected study participants. Then after, Amharic version self-administered structured questionnaires were given to the employees at their institutions during working day time and returned back in the same day.

\section{Data quality Control}

One day of training was given for 2 data collectors (a Woreda health extension officer and Delgi health center health extension officer) and a supervisor (Woreda health insurance focal person) who work in that woreda. 
Then, data collectors had conducted a pre-test assessment by taking $5 \%$ of randomly selected sampling units from other similar populations, Alefa woreda. The questionnaires which were used for data collection were adapted from the different literature review and other similar studies. Based on the pretest result, the questionnaires were modified into a local context. The supervisor monitors check the consistency of questions and gave comments until the end of data collection. The principal investigator assured the data quality through checking completeness and consistency of filled questionnaire, data clearing, and analysis of the data through proper data analysis methods. The data were interred into EPIINFO 7, SPSS v 20, and open code 3.6 twice.

\section{Data processing and analysis}

In EPI INFO version 7, hard copy data were entered and then converted to SPSS version 20 program. Again, the existence of the variables, frequencies, outliers, and recoding of the variables was done before any special research was done, verifying the statement. Descriptive data analysis was then conducted, such as text, charts, diagrams, frequencies, mean, median, quartile, and percentages. For all variables, bivariate logistic regression was carried out to find candidate variables with the enter method for multiple logistic regressions.

Those 9 candidate variables that in the bivariable analysis had a p-value $<0.2$ were entered into the multivariable analysis. Finally, the P-value $<0.05$ result was found to be statistically important in the Multivariate logistic regression model. To see the power of correlation for variables, the Adjusted Odds ratio was used for 95 percent $\mathrm{Cl}$. Bootstrap has been used to see whether or not these observations are in line with another research. Qualitative data were transcribed, interpreted, converted to open-source platform version 3.6, read frequently, coded, and a thematically classified. Finally, through thematic study, it was interpreted.

\section{Results}

\section{Quantitative results}

\section{Socio-demographic characteristics}

Of the 337 total study participants, 324 (96\%) took part in this study, $79 \%$ urban and $21 \%$ rural. All respondents fell between 18 and 62 years of age, with a mean age of 28.12 years (Table 1 ).

Table 1区 Socio-demographic and socio-economic characteristics of employees in Takusa Woreda, 2015 $(n=324)$ 


\begin{tabular}{|c|c|c|c|}
\hline Variables & Category & Frequency (n) & Percentage (\%) \\
\hline \multirow[t]{5}{*}{ Age } & $18-22$ & 32 & 9.9 \\
\hline & $23-27$ & 164 & 50.6 \\
\hline & $28-32$ & 80 & 24.7 \\
\hline & $33-37$ & 16 & 4.9 \\
\hline & $>37$ & 32 & 9.9 \\
\hline \multirow[t]{2}{*}{ Sex } & Male & 182 & 56.2 \\
\hline & Female & 142 & 43.8 \\
\hline \multirow[t]{3}{*}{ Marital status } & Single & 154 & 47.5 \\
\hline & Married & 152 & 46.9 \\
\hline & Others+ & 18 & 5.6 \\
\hline \multirow[t]{4}{*}{ Educational status } & Primary School & 12 & 3.7 \\
\hline & Secondary School & 25 & 7.7 \\
\hline & Diploma & 161 & 49.7 \\
\hline & Degree & 126 & 38.9 \\
\hline \multirow[t]{5}{*}{ Working experiences in years } & $0.5-2$ & 90 & 27.8 \\
\hline & $2.1-4$ & 81 & 25.0 \\
\hline & $5-7$ & 57 & 17.6 \\
\hline & $8-10$ & 52 & 16.0 \\
\hline & $>10$ & 44 & 13.6 \\
\hline \multirow[t]{4}{*}{ Size of household } & $1-2$ & 151 & 46.6 \\
\hline & $3-4$ & 107 & 33.0 \\
\hline & $5-6$ & 44 & 13.6 \\
\hline & $>6$ & 22 & 6.8 \\
\hline \multirow[t]{3}{*}{ Number of dependent children } & No & 200 & 61.7 \\
\hline & $1-2$ & 103 & 31.8 \\
\hline & $>2$ & 21 & 6.5 \\
\hline \multirow[t]{2}{*}{ Number of dependent nuclear children } & No & 240 & 74.1 \\
\hline & $1-2$ & 59 & 18.2 \\
\hline
\end{tabular}




\begin{tabular}{|c|c|c|c|}
\hline & $1-2$ & 59 & 18.2 \\
\hline & $>2$ & 25 & 7.7 \\
\hline \multirow[t]{5}{*}{ Working pool } & ADP & 15 & 4.6 \\
\hline & AGP & 22 & 6.8 \\
\hline & $\mathrm{CP}$ & 22 & 6.8 \\
\hline & CSP & 231 & 71.3 \\
\hline & $\mathrm{OP}$ & 34 & 10.5 \\
\hline
\end{tabular}

NB: + =Widowed, divorced; ${ }^{\circledR}=$ Muslim, Protestant; $@$ C =Tigre, Oromo; ADP: Administration pool; AGP: Agricultural pool; CP: Communication pool; OP: others pool; CSP: Civil service pool

\section{Employees' Monthly net income}

Nearly one third, 29 percent, of the research units had 1500-1999 Ethiopian Birr net monthly revenue (ETB). With a minimum of 500 and a limit of 20,000ETB, the average monthly net employee income was 2,477.17 (Figure 1).

\section{Health and health related characteristics}

Most, $77.5 \%$, workers were able to get a health center, $43.2 \%$ were able to get a private clinic, $37 \%$ were able to get to the hospital, and $21.6 \%$ were able to get a pharmacy nearest health post. Generally speaking, $96 \%$ of them were available for health insurance, while just $4 \%$ were not.

More than half, $54.9 \%$ of study units or their families have been ill for the last 12 months, and the remainder has been well. Out of 180 family sick stories, $44.1 \%$ had been ill for less than 3 days, 26.3\% had been ill for 1 week, and 19\% had been ill for more than 3 weeks. Among the sick respondents, 53.3\% had to get outpatient health care from the health department, $21.4 \%$ had to get help from the private clinic, and $20.5 \%$ from the doctor.

In sick respondents, $49.2 \%$ had paid less than 83 ETB, and $22.3 \%$ had paid more than 360 ETB. Overall, the total amount charged for outpatient sickness in the last 12 months was 548.41 , ranging from 0 (maybe workers, exempted facilities, etc.) to 11,000 . In all the sick 180 participants, only $24.4 \%$ were admitted.

Nearly three-fourths, $71.6 \%$, reimbursement of medical bills was out of pocket, and others, $73.1 \%$ of the state that they were unable to meet all their manufacturing expenses on their own. Furthermore, $67.6 \%$ of workers were unhappy with the consistency of health care delivery (Table 3 ).

Table 3囚 Medical cost payment system and satisfaction of employees in Takusa Woreda, 2015(n=324) 


\begin{tabular}{|llll|}
\hline Questions & Category & Frequency & Percentage \\
\hline Who paid your current medical cost & Self & 232 & 71.6 \\
\cline { 2 - 4 } & Government & 51 & 15.7 \\
\cline { 2 - 4 } & Both & 35 & 10.8 \\
\cline { 2 - 4 } & Others* & 6 & 1.9 \\
\hline Who should cover HS Cost? (n=453) & Customers & 207 & 45.7 \\
\cline { 2 - 4 } & Government & 203 & 44.8 \\
\cline { 2 - 4 } & Both & 53 & 11.7 \\
\hline Can government fund cover all health service & No & 246 & 75.9 \\
\cline { 2 - 4 } & Yes & 79 & 24.1 \\
\hline Out-of-pocket payment cover all output costs & No & 237 & 73.1 \\
\cline { 2 - 4 } & Yes & 87 & 26.9 \\
\hline Satisfaction by health service payment system & No & 216 & 66.7 \\
\cline { 2 - 4 } & Yes & 108 & 33.3 \\
\hline Satisfaction by quality of health service & No & 219 & 67.6 \\
\hline \multirow{2}{*}{ How SHI membership shall be (n=215) } & Voluntary & 198 & 32.4 \\
\cline { 2 - 4 } & Mandatory & 17 & 7.9 \\
\cline { 2 - 4 } & & 105 & 92.1 \\
\hline
\end{tabular}

* = Family, employer

\section{Awareness and attitude characteristics}

Among all, $66.7 \%$ of study units replied as they understood what SHI was, but just about a third, $34 \%$ of employees were well aware of SHI. The bulk of workers, $70.1 \%$, had a favorable attitude, while $29.9 \%$ had an unfavorable attitude towards the SHI system (Table 4).

Table 4囚 Attitude of governmental employees for SHI in Takusa woreda, $2015(n=324)$ 


\begin{tabular}{|llll|}
\hline Variables & Category & Frequency & Percentage \\
\hline I'm healthy enough that I really don't need SHI & Yes & 227 & 70.1 \\
\cline { 2 - 4 } & No & 97 & 29.9 \\
\hline I think SHI is not worth the money it cost & Yes & 131 & 40.4 \\
\cline { 2 - 4 } & No & 193 & 59.6 \\
\hline I'm more likely to take risks than the average person & Yes & 250 & 77.2 \\
\cline { 2 - 4 } & No & 74 & 22.8 \\
\hline I can overcome illness without help from a medically & Yes & 278 & 85.8 \\
\cline { 2 - 3 } & No & 46 & 14.2 \\
\hline $\begin{array}{l}\text { SHI would not solve the premium of health service } \\
\text { expense }\end{array}$ & Yes & 249 & 76.85 \\
\cline { 2 - 4 } & No & 75 & 23.15 \\
\hline Attitude & Unfavorable & 97 & 29.90 \\
\cline { 2 - 4 } & Favorable & 227 & 70.10 \\
\cline { 2 - 4 }
\end{tabular}

\section{Source of information}

The awareness-building exercise, accompanied by TV, was the primary source of knowledge for SHI (fig 2).

\section{Demand of Social Health Insurance}

The $61.1 \%$ of respondents had strong demand, equivalent to two-thirds, while the remaining $38.9 \%$ had poor demanded (Figure 3). The mean monthly payment was 2.23 out of 208 research units that able to pay, varying from $0.01 \%$ to $8 \% .34 .9 \%$ were afraid of low-quality health care provision, $27.4 \%$ were due to insecurity, among those who were not able to participate and pay for SHI membership. The remaining $16.4 \%$ denied should get free health care because of health workers it may be influenced by corruption; payment of imbalance and service received a lack of understanding.

\section{Factors for Demand of SHI}

In the binary logistic regression model, nine variables were eligible to be interred into multiple logistic regression $(p<0.2)$. But in the multiple regression model, only three variables which are rural residence $(p=0.039)$, family size $(p=0.04)$, and cost of outpatient treatment during illness in the last 12 months preceding the data collection period $(\mathrm{p}=0.006)$, were found to be associated with demand of $\mathrm{SHI}$ among employees $(p<0.05)$. 
Employees who had 5-6 family sizes were 5.5 times more likely to had a demand for SHI as compared to those who had 1-2 family size ( $A O R=5.50,95 \% \mathrm{Cl}=1.01-30.08)$. It was also found that for rural residents, the likelihood of SHI demand was 3.3 times higher than for urban residents (AOR=3.29, 95 percent $\mathrm{Cl}=$ 1.06-10.20). In comparison, workers who charged more than 360 ETB for outpatient care during sickness in the last 12 months were 5.2 times more likely than those who paid less than 83ETB (AOR= 5.22, 95\% $\mathrm{Cl}=1.61-16.95)$ to have a demand for SHI compared to those who paid less than 83ETB (Table 5).

Table 5ロAssociated factors for demand of SHI among employees in Takusa Woreda, 2015 ( $n=324)$ 


\begin{tabular}{|c|c|c|c|c|c|}
\hline \multirow[t]{2}{*}{ Variables } & \multirow[t]{2}{*}{ Category } & \multicolumn{2}{|c|}{ SHI Demand } & \multirow[t]{2}{*}{$\operatorname{COR}(95 \% \mathrm{Cl})$} & \multirow[t]{2}{*}{ AOR (95\%Cl) } \\
\hline & & Poor & Good & & \\
\hline \multirow[t]{2}{*}{ Attitude } & Unfavorable & 26 & 18 & 1 & \\
\hline & Favorable & 100 & 180 & $2.6(1.36-4.97)$ & $2.90(0.80-10.52)$ \\
\hline \multirow[t]{4}{*}{ Family size } & $1-2$ & 66 & 85 & 1 & 1 \\
\hline & $3-4$ & 42 & 65 & $1.20(0.73-1.99)$ & $1.33(0.40-4.38)$ \\
\hline & $5-6$ & 10 & 34 & $2.64(1.22-5.73)$ & $5.50(1.01-30.08) *$ \\
\hline & $>6$ & 8 & 14 & $1.36(0.54-3.43)$ & $5.41(0.51-57.04)$ \\
\hline \multirow[t]{2}{*}{ Residence } & Urban & 107 & 149 & 1 & 1 \\
\hline & Rural & 19 & 49 & $1.85(1.03-3.32)$ & $3.29(1.06-10.20)$ * \\
\hline \multirow[t]{4}{*}{ Marital status } & Single & 69 & 85 & 1 & 1 \\
\hline & Married & 51 & 101 & $1.61(1.01-2.55)$ & $1.86(0.63-5.23)$ \\
\hline & Others & 6 & 12 & $1.62(0.58-4.55)$ & $1.71(0.15-19.69)$ \\
\hline & Others & 9 & 5 & 1 & 1 \\
\hline \multirow[t]{3}{*}{ Dependent children } & 0 & 86 & 114 & 1 & 1 \\
\hline & $1-2$ & 37 & 66 & $1.35(0.82-2.20)$ & $0.61(0.22-1.69)$ \\
\hline & $>2$ & 3 & 18 & $4.53(1.29-15-86)$ & \\
\hline \multirow[t]{3}{*}{ Nuclear children } & 0 & 105 & 135 & 1 & 1 \\
\hline & $1-2$ & 15 & 44 & $2.28(1.20-4.32)$ & $2.46(0.86-7.04) 7$ \\
\hline & $>2$ & 6 & 19 & $2.46(0.95-6.39)$ & $0.69(0.167-2.82)$ \\
\hline \multirow[t]{5}{*}{ Cost of Treatment } & $<83$ & 31 & 57 & 1 & 1 \\
\hline & $83-130$ & 9 & 12 & $0.73(0.28-1.91)$ & $0.47(0.14-1.58)$ \\
\hline & $131-215$ & 5 & 13 & $1.41(0.46-4.34)$ & $1.66(0.46-6.07)$ \\
\hline & $216-360$ & 5 & 7 & $0.76(0.22-2.6)$ & $1.19(0.30-4.77)$ \\
\hline & $>360$ & 5 & 35 & $3.81(1.35-10.71)$ & $5.22(1.61-16.95) *$ \\
\hline \multirow[t]{2}{*}{ Health status } & Healthy & 71 & 75 & 1 & 1 \\
\hline & Sick & 55 & 123 & $2.12(1.34-3.34)$ & $2.90(0.80-10.52)$ \\
\hline
\end{tabular}

*=Those variables which had significances association $(p<0.05)$ 


\section{Qualitative findings}

\section{Awareness related characteristics}

Twelve workers, six men, and six women were interested in 2 FGDs in total. Of these, 8 were professional health professionals. Nearly all FGD respondents were well educated about SHI. SHI was described by the head of the Delgi Health Center as "Like rich people purchasing a car and insuring it, SHI was a way for members to pay based on their income to become a member." A district hospital manager stated the condition as "...All paid members may not get health services by chance, but like other organizations such as 'Eddire' by understanding this it was an opportunity in which one would help others."

\section{Health institution that would provide SHI service}

In the thematic analysis, half of the respondents agreed as any accredited health institution which was voluntary to provide the service would be delegated. The head of Delgi health center said that "... Gambi Hospital can give the service in collaboration with Felegehiwot referral Hospital. Since as they are qualified and present inside Ethiopia..." On the other hand, a 25 years old female stated that "... start the service by governmental health institutions followed by private institutions based on the standards. If any institutions did not fulfill the standard it would be better to upgrade it through time ..."

Contrarily, half of them respond as only governmental health institutions, excluding health post would provide the service. A small enterprise officer complains as "private health institutions were profit finders, they might need to collect over income... if one person was ill and goes there, the customer would pay 70100 birr for a card only. If it was for Laboratory, drugs, and other services, we can estimate how much he would pay."

\section{Preparedness of health institutions}

Regarding the preparedness of health institutions, the majority of FGD study groups replied as almost all of them were as it was. Health institutions that would take contract agreement were not selected; lack of additional manpower, classrooms, supplies; lack of discussion forum and promotion; lack of infrastructure; unpreparedness of membership files were some of the indicators. A Nurse employee said that "... in our woreda among five health centers, 2 of them hadn't, even once, the medical laboratory professional.” A 25 year's old employee responds as "...Still, those health institutions which will provide the service are not identified. It indicates as there was no preparedness. The manpower, classes, and other inputs are as previous." A 32 years old nurse said that "employers hadn't any idea about SHI...they didn't know how much percent they would pay for their employee, how would pay it..."

\section{Scope of SHI program}

Thematic analysis showed that the scope of SHI services would be all health services, except beauty, at any time and place up to abroad referral system including both medical \& non-medical related costs. A Small enterprise officer, 42 years old, said that "...SHI must provide all health services at any time and any 
place, except those done for beauty. There must be a referral system from Woreda up to specialized Federal Hospitals, even outside of the country. Unless it incorporates complicated services why it needs to be a member of SHI because he can get simple health services by himself..." Majority of them also agreed as all employee's would-be member of $\mathrm{SHI}$.

A 28 years old district hospital manager said that "... when I see mine, it would be 117.33ETB per month. I should save it... since I am health professionals, had better awareness about the disease, and I can care for myself from the disease." He also stated his fear as "...If members paid consecutively and unfortunately, they did not get health service by SHIA due to being healthy, they might think paying without benefit...". They also mentioned that members might be enforced by health professionals to give referral papers for them whether the case was beyond the scope of contracted health institutions or not.

\section{Strength and weakness of SHI scheme}

According to Delgi health center head, SHI had holistic profits. He stated it as "... when health institutions were strengthened, supplies would be accessible and then accessible quality service would be given to members. It also reduces those ill persons that stayed at home due to shortage of money..." A 32 years old environmental health officer expressed the strength of SHI as "... civil servants' health-seeking behaviors would be increased. When they were felt ill, they would come to get treatment. SHI was used as retires. In the retires program, some percent of the money was collected throughout their active working time and it would be used at the time of passive employment. SHI was just like this; the income was collected during the healthy time and used when they were ill'. The majority of them agreed as the SHI program provides both prevention and treatment services. They state it as, when members feel simply ill, they would come and got health service, pieces of advice about health education, because they had no financial problems. So, this can be considered as preventive as well as curative. On the other hand, participants respond as SHI had its weakness. A 25 female raised the issue in that "... membership payment, and its benefit was not balanced. Even after paying this amount of money, complicated health services were not provided..."

Table 6: Strength and weakness of SHI in Takusa Woreda, 2015 


\begin{tabular}{|ll|}
\hline Strength & Weakness \\
$\begin{array}{l}\text { Provide both Preventive and } \\
\text { treatment }\end{array}$ & $3 \%$ payment too high \\
$\begin{array}{l}\text { Health seeking behavior } \\
\text { increases }\end{array}$ & Restriction of health services \\
\hline $\begin{array}{l}\text { Accessing quality health } \\
\text { services }\end{array}$ & $\begin{array}{l}\text { Imbalance membership payment between SHI \& CBHI with equal } \\
\text { health service consumption }\end{array}$ \\
\hline $\begin{array}{l}\text { Give universal health } \\
\text { services }\end{array}$ & Non refunded collected money \\
$\begin{array}{l}\text { Strength finance of health } \\
\text { institutions }\end{array}$ & Imbalanced membership payment \& benefit \\
\hline $\begin{array}{l}\text { Reduce out of pocket } \\
\text { payment }\end{array}$ & Being member of SHI by mandatory \\
\hline
\end{tabular}

\section{Sustainability of SHI program}

A thematic content analysis revealed that to increase uptake of $\mathrm{SHI}$ and to sustain it, inputs should be fulfilled timely. A male Nurse who was 30 years old stated as "... to sustain SHI program, pharmaceutical fund supply agency should have fast dispatching system of inputs to health institutions..." Also, a 25 year's old female said that "...the idea should not be declared from administrative bodies only and forwarded to members. Rather, it was better to discuss with employees and customize with our country context..." She also said that "....as membership monthly payment was too much it was better to create a discussion forum and then after arriving on consensus to increase by starting from smallest monthly payment system..."

This study revealed that the following indicators were enabling factors for good demand of SHI in the future.

- Use networked finance system

- Conduct discussion forum

- Maintain quality of health service

- Reduce payment

- Start CBHI as a role model

- Do HI preparedness assessment

- Auditing HI regularly

- Prevent corruption

- Monitor the program

- Avail inputs

- Promote SHI 
- Voluntariness based SHI

- Assign responsible body

- Unify 3 type of HI

\section{Discussion}

In this study, the demand of employees for SHI was $61.1 \%$. It revealed that family size, rural residence, and cost of treatment were positively associated with the demand for SHI. The demand for this study, $61.1 \%(95 \% \mathrm{Cl}=55.6-66.7 \%)$, was greater than that of Jimma, $51.5 \%$, and Wolita Sodo, $54 \%$ [18-19]. It might be due to employees in this study were financially secured; had greater confidence in the implementation and benefit of the newly proposed program; had high intension to help risk groups, quality health service provision, had relatively better awareness than the Jimma community, and Wolita Sodo teachers.

The willingness of employees to join SHI in Takusa woreda $(69.10 \%)(95 \% \mathrm{Cl}=64.2-74.2)$, was less than that of Iran (98.62\%), Namibia (86.74\%), Ghana (91\%), South Africa (74.5\%), Tanzania (80\%) and Fogera District in Ethiopia (80\%) [18-22]. This might be due to the HI program was in the infancy stage in Ethiopia in general, it had already started in other countries like Fogra. As a result, its benefit would be well known, and uptake of health insurance would be increased. The other explanation might be due to variation of socio-demographic and economic factors.

But it was greater than that of Nigeria (52.5\%) [23] and Jimma (51.5\%) [19]. It might be due to Takusa woreda employees were relatively financially well secured than Nigeria (literature shows that Populations who live below the poverty line in Ethiopia (27.8\%) was less than that of Nigerian (70.2\%) and Jimma. The other reason might be due to variation of study units, household heads in Jimma, and Secretariat in Nigeria. Surprisingly this finding was in line with that of China (70\%) [24] and Wolita Sodo (71.3\%) [18].

The willingness to join $\mathrm{SHI}$ in this study was also supported by a qualitative study. More than half of them agreed to join SHI by putting preconditions. A 25 years old female stated as "I am voluntary to join SHI however, the idea must not be decided by the authoritative body only ... Rather it would be better to have discussion forum between employees and authorized body and able to amend accordingly". In this study, Willingness to pay for $\mathrm{SHI}, 64.2 \%(95 \% \mathrm{Cl}=59.3-69.4 \%)$, was greater than that of Lose Angeles,54\% [25]. It may be due to Takusa woreda civil servants were almost sedentary while Mexican were immigrants who live in Lose Angeles. Also, it was more than done in Namibia, 42.25\% [21]. This might be due to the implemented health insurance program in Namibia did not cover all components of health services, and members might be dissatisfied. Again, it was greater than that of Wolita Sodo in 2012, which was $53.1 \%$. It might be due to net income and awareness of this study participants were better than Wolita Sodo teachers [18]. But it was less than a study done in Fogera Woreda in 2013 on community. The possible justification for this community might be their wealthiness through rice production. Its benefit might be the well-known quality of health service might be improved; due to environmental conditions, they might be more vulnerable to diseases like malaria. 
Though $64.2 \%$ were willing to pay, only $61.1 \%$ had good demand for SHI. The discrepancy $(3.09 \%)$ might be due to the participants could pay, but they were not voluntary to join the SHI scheme. They might be health practitioners, Bank professionals, polices, etc. who were not paid for medical bills in the former health service provision system and others. This was supported by FGD results. A 28 years old district hospital manager said that "I will not be members of SHI. Because I am health service providers, which make me more vulnerable to occupationally related diseases. So, I should get the service freely... on the other hand, as a health professional, I can promote my health better than non-health professionals".

Increment of SHI demand as FS increases in this study was supported by the study conducted in Fogera and Ghana [22, 26]. It might be due to as the size of the household increases, the financial burden faced by households during illness to get health care services increases and health insurance participation would rise. However, in Zimbabwe family size was associated negatively [27]. It might be due to an increment of payments for $\mathrm{CBHI}$ membership, as the family size rises, which leads to unaffordable, and hence a family might decide to withdraw from the program. This may be seen when there were no chronic illnesses in the family and yet family income is low.

It was also found that participants who live in rural areas were 3.3 times more likely to had SHI demand compared to urban residents. This might be rural employees were not well resourced financially as compared to urban; they might mostly vulnerable to diseases because they were far from health information to had a self-car, inaccessible for health services. Culture and belief-systems of the rural area might be increased the probability of their illness. Due to these, their intention to enroll in the SHI program might be increased. Moreover, the increment of uptake of SHI, as the cost of health service payment increased, in this study was supported by research done in Pakistan [28]. It might be due to as people became ill and their medical bills increased, their demand for SHI might be raised.

The main reasons for the poor demand for SHI in this study were similar to that of Jimma, Wolita Sodo, and Fogera [18-19, 22]. These were: poor quality of health services; Poverty; fear of poor implementation; feeling of being healthy; the pocket payment was better and restriction of health service provision. This was supported by a qualitative study. It revealed that inputs like water, light, equipment, drugs, manpower were scarce; health professionals were not responsible and accountable for their work.

The majority of FGD participants agreed that preparedness of health institution which would provide SHI services was as it was. A Nurse employee said that "... in our woreda among five health centers, 2 of them hadn't, even once, the medical laboratory professional." Again a 25 year's old employee responds as "...Still, those health institutions which would provide the service were not identified... there is no any preparedness... manpower, classes and other inputs are as previous." A 28 years old district hospital manager said that "...If members paid consecutively and unfortunately, they did not get health service by SHIA due to being healthy, they might think paying without benefit...". They also stated as members might enforce health professionals to give referral papers for them whether the case was beyond the scope of contracted health institutions or not. 
The other main factor which would reduce the uptake of SHI was the scope of health services provided by SHIA. Thematic analysis showed that the scope of SHI services would be all health services, except beauty, at any time and place up to abroad referral system including both medical \& non-medical related costs. A small enterprise officer said that "unless it incorporates complicated services why it needs to be a member of SHI because anyone can get simple services by themselves."

Type of health institution that provides SHI service were another fear employee for the quality of SHI service provision. Half of the respondents agreed as any accredited health institution which was voluntary to provide the service would deliver the service. Contrarily, half of them respond as only governmental health institutions, excluding health post would provide the service. A Small enterprise officer complains as "private health institutions were profit finders, they may need to collect over income... if one person was ill and gone to their customers would pay 70-100 birr for a card only. If it was for Laboratory, drugs, and other services, we can estimate how much he would pay."

In general, a qualitative study revealed that the main constraints for successful implementation of SHI would be SHIA related factors, SHI provider health institutions, employees' related factors, and other factors. The quantitative study was triangulated with a qualitative study. The main limitations for this study were recall bias on money paid for health care and illness episode in the family, and preparedness of health institutions were assessed by FGD instead of facility auditing.

\section{Conclusions}

Generally, when the result of this study was compared with most studies, it was greater than Ethiopians but less than abroad. In this study, family size, rural residence, and the maximum cost of outpatient treatment were found to be positively associated with good demand for SHI. Though the majority of study units had poor awareness, most of them had a good attitude and demand for SHI. It indicates as if an awareness creation session was conducted with different modes and preconditions were fulfilled, their intention to uptake SHI would be enhanced. To have good demand for SHI, this study demonstrated to conduct awareness creation session forum; maintain quality of health service, prepare health institutions and use of networked finance system was the predominant enabling factors.

We recommended the social health insurance agencies to conduct awareness creation sessions about health insurance and its benefits to employees, and to select institution which takes contract; conduct audit and trust assessment regularly, Regional Health Bureau and Ministry of Health to advocate SHI by mass media to enhance its policies regarding medical record system, information utilization to support effective implementation of $\mathrm{SHI}$, and researchers to do further investigation on $\mathrm{SHI}$, especially on quality of health service and preparedness of health institutions.

\section{Acronyms And Abbreviations}


BHI: Basic Health Insurance, CBHI: Community Based Health Insurance, FMOH: Federal Ministry of Health, FGD: Focused Group Discussion, HCF: Health Care Finance, HI: Health Insurance, HIS: Health Insurance System, NHIF: National Health Insurance Fund, NHIS: National Health Insurance Scheme, SHI: Social Health Insurance, SHIS: Social Health Insurance Scheme, SPSS: Statistical Package for Social Science, UoG: University of Gondar, WTP: Willingness to Pay, WTJ: Willingness to Join

\section{Declarations}

\section{Ethical considerations}

Ethical clearance was obtained from Review Committee of University of Gondar College of medicine and health science Institute Public Health. Permission Letters was obtained from administration and Health office. Informed written consent was obtained from respondents. Data collectors informed the study participants about their right to give, interrupt or refuse to give the data and its confidentiality would be maintained.

\section{Consent for publication}

Not applicable

\section{Availability of data and materials}

The original data are available at the corresponding author, so that an interested reader can get the data from the corresponding author with reasonable request.

\section{Competing interests}

The authors declared that they have no competing interests regarding the publication of this article

\section{Funding}

Not applicable

\section{Authors' contributions}

TG: Conceptualization of the idea of the study. TG, MY, and AF were participated in the data collection, data curation, analysis, and interpretation of the data. MG and GA were participated in data collection and analysis. All authors were actively participated for the manuscript preparation and finalization of this article. All authors read and approved the final manuscript.

\section{Acknowledgments}

We would like to express my deepest gratitude to University of Gondar for launching this master's program. We also would like to thank supervisors, data collectors, study participants, our families, friends 
and others who supported us from the beginning to the end of this research.

\section{References}

1. Ethiopian health insuranc agency. Importance of health insurance and the role of government, E.H.i. agency, Editor 2013, Fedral ministry of health: Ethiopia.

2. Health FD. R.o.E.M.o., Health insurance strategy, F.M.o.H.p. guidline. Editor: Fedral Ministry of Health Ethiopia; 2000.

3. Ravi P, Shanaz WI. S, Assessment of Social Health Insurance Feasibility and Desirability in Fiji, Organization WH. Editor 2013, Minister of Health: Sri Lanka.

4. Ursula G, Yadira EA. D, The Impact of Universal Coverage Schemes in the Developing World: A Review of the Existing Evidence, Bank TW. Editor 2013, Washington DC: Washington DC.

5. WHO. The Path to Universal Health Coverage, in Plan of Action H.S. Financing:, Editor 2012, WHO Document Production Services: Geneva, Switzerland.

6. Guy C. C.J., Social health insurance: Key factors affecting the transition toward suniversal coverage. World Health Organization 2005. 58(1).

7. Charlotte H, Tasneem NP, Vaibhav Sanjay K, Girmay S, Joshua M. S, Challenges and Opportunities for Implementing Integrated Mental Health Care: A District Level Situation Analysis from Five Lowand Middle-Income Countries. 2014.

8. Ole D. B.S., Jean-O, The Benefits and Challenges ofSocial Health Insurance for Developing and Transitional Countries 2006, Federal Ministry for Economic Cooperation and Development (BMZ): German.

9. C. SOCME, The effect of social health insurance on prenatal care Springer Science Business Media New York, 2014.

10. FMOH. Impotrance of $\mathrm{HI}$ and the role of government, H.i. agency, Editor 2013, Fedral ministry of health: Ethiopia.

11. Bank, TW.GOVERNING MANDATORY HEALTH INSURANCE. 2008: Washington DC.

12. Africa, Suport our live saving work in Ethiopia. Canadian Network for International Surgery, 2011.

13. health Mo. Health in Ethiopia, in Fact Sheets 2015, Fedral Democratic Repiblic of Ethiopia: Ethiopia.

14. Bank W. Life expectancy at birth 2014.

15. Gazeta HPR,FNegarit. in Federall Negarit gazeta of the federal Democratic Repuplic Of Ethiopia2010, House of people and representative of Ethiopia: Addis Ababa.

16. C N. Poor Access to Health Services: Ways Ethiopia is Overcoming it, in Research Commentary2007, Population Action International: Washingtonl.

17. Office TWH. Health Report of Takusa Woreda. 2014/15.

18. al TAe, WILLINGNESS TO JOIN AND PAY FOR THE NEWLY. PROPOSED SOCIAL HEALTH INSURANCE AMONG TEACHERS IN WOLAITA SODO TOWN. Ethiop Health Science, 2014. 24(3). 
19. F AM. Predictors of Willingness to Participate in Health Insurance Services Among the Community of Jimma Town. Librates Academia. 2014;7:31-7.

20. Jane G, John JA, August A, Josephine K, Bronwyn B. H,et al, Social solidarity and willingness to tolerate risk- and income-related cross-subsidies within health insurance. Oxford University. 2012;27(10):55-63.

21. Abay A,Willingness to Pay for Health Insurance: An Analysis of the Potential Market for New Low Cost Health Insurance Products Center for Disease Control and Prevention\National Institute for Occupational Health \& Safety (USA) 2008.

22. Adane Kebede MG, Yitayal M, Willingness to pay for community based health insurance among households in the rural community of Fogera District, North West Ethiopia. International Journal of Economics, Finance and Management Sciences, 2014.

23. Olugbenga-Bello Al, KNOWLEDGE AND ATTITUDE OF CIVIL WA, SERVANTS IN OSUN STATE,SOUTHWESTERN NIGERIA TOWARDS THE NATIONAL HEALTHINSURANCE. Nigerian Journal of Clinical Practice. 2010;13(4):421-6.

24. Till B, Xinping YL Z and Rainer S. Willingness to Pay for Social Health Insurance among Informal Sector Workers. BMC Health Services Research, 2007. 7(114).

25. Miguel AG, B.A.V.B. and L.A.I.d.I.S.A.M.n. Cardoso, Redressing the Limitations of the Affordable Care Act for Mexican Immigrants Through Bi-National Health Insurance: A Willingness to Pay Study in Los Angeles.

26. Ackah C. O.A., Assessing the Knowledge of and Attitude towards Insurance in Ghana. 2012.

27. University FMMS. Health insurance determinants in Zimbabwe: Case of Gweru Urban. Journal of Applied Business and Economics, 2013. 14.

28. Sarwar C, Hamza AQ, AWARENESS AND WILLINGNESS TO BUY PRIVATE HEALTH INSURANCE A. AND A LOOK INTO ITS FUTURE PROSPECTS IN PAKISTAN. European Journal of Business and Social Sciences, 2013. 2.

\section{Table 2}

Table 2 was not provided with this version

\section{Figures}




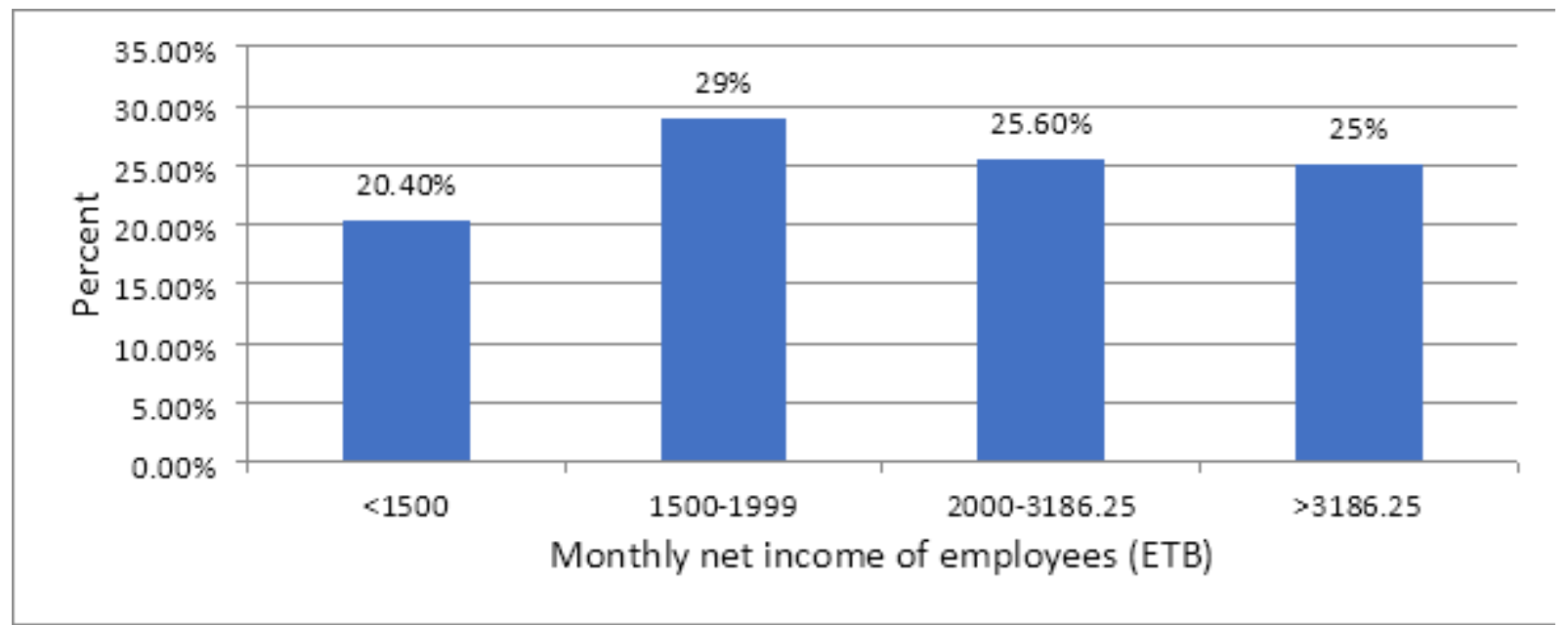

\section{Figure 1}

Monthly net income of Takusa Woreda employees, 2015 ( $n=324)$

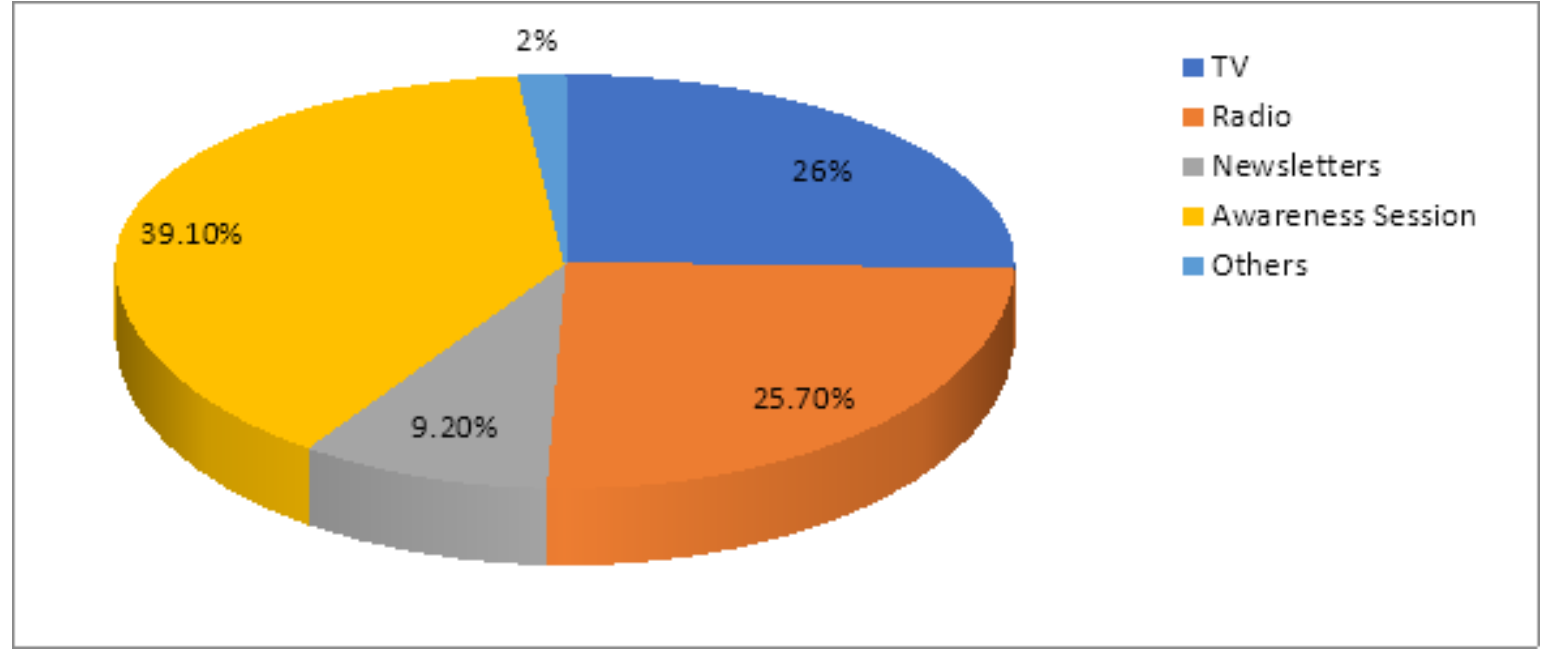

Figure 2

Source of information for SHI among employees in Takusa Woreda, $2015(n=216)$ 


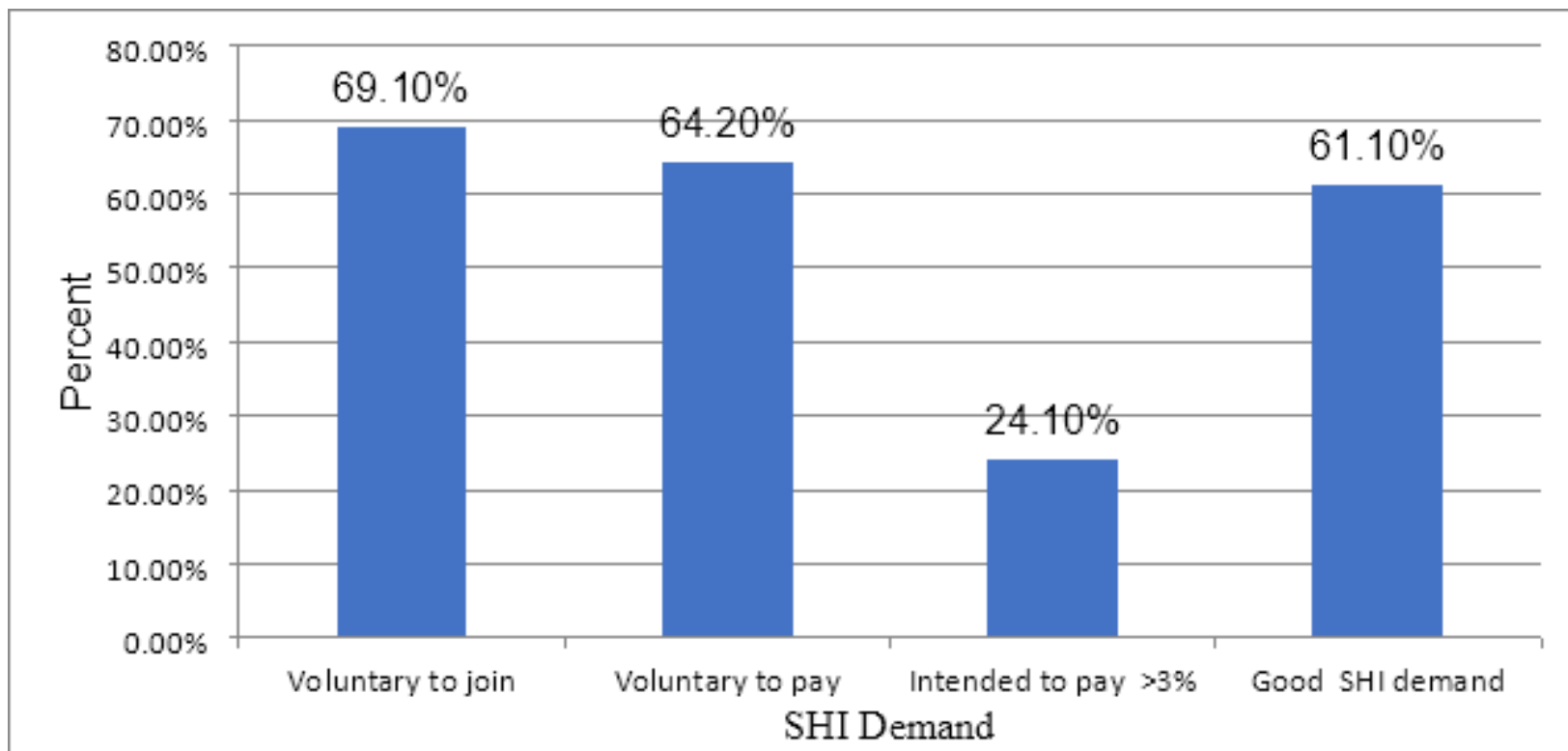

Figure 3

Demand of SHI among employees in Takusa Woreda, 2015 